\title{
The Impacts of Inconsistent Status Quo Evaluations on Regional War*
}

\author{
Wooksung Kim • Choong-Nam Kang \\ (Seoul National University · University of Texas at Tyler)
}

$\langle$ CONTENTS $\rangle$
I . Introduction
1. Unit of Analysis and Sample
II . Inconsistency of Status Quo
2. Variables and Method
Evaluations
IV . Empirical Analysis
III . Research Design
V. Conclusions

- Keywords : power transition, multiple hierarchy model, status quo evaluation, regional war, inconsistent status quo evaluations

\section{[ABSTRACT】}

The purpose of this study is to extend Lemke's multiple hierarchy model of power transition theory by introducing two different dimensions of status quo evaluations of regional contenders. Since a state's status quo evaluations are involved at two different levels - the regional and the global - and a challenger's dissatisfaction is one of the important conditions for the onset of war, the study of regional war, war between regional contenders in particular, should take into consideration both status quo evaluations of states. We argue that not only the regional status quo evaluation but also the global status quo evaluation affects the probability of a regional war between a regional

* The earlier version of this article was presented at the annual meeting of the International Studies Association, New York, February 16, 2009. We would like to thank Doug Lemke for generously sharing his data. We also thank three anonymous reviewers for their comments and suggestions. Our thanks also go to Shane Axtell and Wayne Taylor for their helpful suggestions. 
challenger and a dominant state. We also claim that when the two states' status quo evaluations are in opposite directions, they are much more likely to go to war because the change of a regional status quo can affect the global status quo and, thus, regional conflict contending over the regional status quo is more likely to invite the intervention of global contenders. The results of a statistical analysis support our hypothesis.

\section{I . Introduction}

Power transition theory, as a systemic level theory, provides a plausible explanation for the causes of the stability and change of the international system including major power war. Since Organski ${ }^{1)}$ and Organski and Kugler $^{2)}$ have developed power transition theory, a great deal of theoretical and empirical work has been added to this research program by a number of scholars. ${ }^{3)}$ These accumulations have contributed to the progress of the power transition research program based on Lakatosian criteria.)

1) A. F. K. Organski, World Politics (New York, NY: Alfred A. Knopf, 1958).

2) A. F. K. Organski and Jacek Kugler, The War Ledger (Chicago, IL: University of Chicago Press, 1980).

3) See Woosang Kim, "Alliance Transitions and Great Power War," American Journal of Political Science 35-4 (1991), pp. 833-50; "Power Transitions and Great War from Westphalia to Waterloo," World Politics 45-1 (1992), pp. 153-72; "Power Parity, Alliance, and War from 1648 to 1975," in Jacek Kugler and Douglas Lemke (eds.), Parity and War: Evaluations and Extensions of The War Ledger (Ann Arbor, MI: University of Michigan Press, 1996), pp. 93-106; Douglas Lemke and Suzanne Werner, "Power Parity, Commitment to Change, and War," International Studies Quarterly 40-2 (1996), pp. 235-60; Suzanne Werner and Douglas Lemke, "Opposites Do Not Attract: The Impact of Domestic Institutions, Power, and Prior Commitment on Alignment Choices," International Studies Quarterly 41-3 (1997), pp. 529-46; Kelly M. Kadera, "The Conditions and Consequences of Dyadic Power Transitions: Deductions from a Dynamic Model," in Kugler and Lemke (1996), pp. 287-312; Douglas Lemke, Regions of War and Peace (New York, NY: Cambridge University Press, 2002).

4) Jacek Kugler and Douglas Lemke, "The Power Transition Research Program: Assessing Theoretical and Empirical Advances," in Manus I. Midlarsky (ed.), Handbook of War 
Among the research, Lemke's effort to extend power transition theory to the regional level is one notable example of this progress. Lemke's multiple hierarchy model claims that a power hierarchy exists not only at the global level but also at the regional level, and that the core logic of power transition theory can be applied to the regional level. After defining several local hierarchies based on the ability to interact with one another militarily, he finds that the core power transition argument explaining war with power parity and dissatisfaction is also very useful to account for the causes of regional war between a regional dominant state and a challenger."

Although Lemke's multiple hierarchy model is a major contribution to the empirical and theoretical progress of the power transition research program, his extension remains incomplete in one area. That is, he does not consider a regional challenger's status quo evaluations as well as those of a regional dominant state at two different levels (global and regional) simultaneously in his analysis, while he develops and justifies an appropriate measure of dissatisfaction at the regional level in the regional context. All states have two different levels of status quo evaluationsglobal and regional levels, and a state's regional status quo evaluation can be different from its global status quo evaluation. Some states are satisfied with the regional status quo while they are dissatisfied with the global status quo or vice versa. On the other hand, some states are satisfied (or dissatisfied) with both status quos. For instance, Japan can be considered a state satisfied with the global status quo maintained by the United States while simultaneously it can be considered a state dissatisfied at the regional level due to China's growing influence in the region and changing of the regional order into one favorable to China's interests. ${ }^{6}$ ) This is not a

Studies II (Ann Arbor, MI: University of Michigan Press, 2000), pp. 129-63; Jonnathan M. DiCcico and Jack S. Levy, "The Power Transition Research Program: A Lakatosian Analysis," in Colin Elman and Miriam F. Elman (eds.), Progress in International Relations Theory: Appraising the Field (Cambridge, MA: MIT Press, 2003), pp. 109-58; Michelle Benson, "Extending the Bounds of Power Transition Theory," International Interactions 33-3 (2007), pp. 211-25.

5) Lemke (2002).

6) It could be argued that several ongoing regional issues between China and Japan 
unique case; rather, we can witness many examples in world history. In this context, if we follow the core logic of power transition theory to explain regional war and accept that dissatisfaction is one important factor in the occurrence of war, between a regional challenger and a dominant state in particular, we need to consider the status quo evaluations at both levels.

Our research starts from this point. What if a regional challenger and a dominant state's status quo evaluations are different at both the regional and global levels? Do these different status quo evaluations of a regional challenger and a dominant state at the global and regional levels affect the probability of war between them? What if a challenger as well as a dominant state is dissatisfied (or satisfied) with the regional status quo while it is satisfied (or dissatisfied) with the global status quo? Are they more likely to go to war against each other? These are the questions we explore in this article.

In a nutshell, we argue that not only the regional level status quo evaluation but also the global level status quo evaluation affects the probability of war between a regional challenger and a dominant state, and that when the two states' status quo evaluations are in opposite directions, they are much more likely to go to war. In the following section, after conceptualizing the inconsistency of the status quo evaluations at both the global and regional levels for a regional challenger and a dominant state,

concerning some territorial disputes and issues related to the two countries' past colonial history represent that both states are dissatisfied with the regional status quo. With respect to this point, power transition theory originally assumes that a dominant power (both at the regional and the global level), by definition, is satisfied with the status quo since the status quo is established and maintained by a dominant power. However, this does not mean that a dominant state is satisfied with all regional issues and/or all aspects of the status quo. Rather, a dominant state should be viewed as being satisfied with the status quo in general while it could be dissatisfied with a specific issue. In this sense, although a regional dominant state can be engaged in conflicts with a challenger state concerning various regional issues, this does not automatically mean that the dominant power is dissatisfied with the regional order since the disputes can be an attempt by the dominant state to defend or make the status quo more favorable to the dominant state. Therefore, a dominant state's satisfaction should be judged more comprehensively and its involvement in disputes should not be viewed as evidence of a dominant power's dissatisfaction with the status quo in general. 
we explain how the inconsistency of the status quo evaluations has an increasing impact on the outbreak of regional war. In the last section, we conduct an empirical test of our hypothesis.

\section{II . Inconsistency of Status Quo Evaluations}

While the power parity between a dominant power and a challenger can be relatively easily applied to the regional level when extending power transition theory to the regional level, the status quo evaluation of a challenger needs to be taken into more careful consideration. A state's status quo evaluation has two dimensions: one dimension concerns the regional status quo and the other is relevant to the global status quo. A regional dominant state establishes a regional status quo regarding local issues in the same manner as the global dominant power creates and maintains the global status quo. As some power transition theorists insightfully suggest, ${ }^{7)}$ a local status quo is more likely to be related to regional issues such as territorial issues or some specific policy issues that are relevant within a local context and provides states with short-term or myopic interests. Meanwhile, the global status quo is more concerned with macro and global issues such as rules, norms, international political and economic orders or international regimes ensuring states a long-term interest, rather than a specific issue. ${ }^{8)}$ The global dominant power, however, does not set up all regional status quos regarding specific regional issues. As long as a regional status quo is not critical or is not a threat to the global order, the global dominant power would allow a regional status quo even though the dominant power keeps implicitly and explicitly trying to change it in favor of itself. ${ }^{9)}$

7) Lemke and Werner (1996) and Kugler and Lemke (2000) are good examples.

8) Kugler and Lemke (2000).

9) Glenn Palmer and T. Clifton Morgan, A Theory of Foreign Policy (Princeton, NJ: Princeton University Press, 2006); "Power Transition, the Two-Good Theory, and Neorealism: A Comparison with Comments on Recent U.S. Foreign Policy," International Interactions 33-3 (2007), pp. 329-46. 
Therefore, there are two different kinds of status quo and all states have two different kinds of status quo evaluation, i.e., global and regional status quo evaluations. Accordingly, it is very hard to say that all states have consistent status quo evaluations between the global and regional levels. Some states can be satisfied with both the regional and global status quos, the global dominant power in particular. Others, however, can be satisfied with the global status quo but not the regional status quo or vice versa, or are satisfied with neither one. This is the same for both a regional dominant state and a challenger state. A regional dominant state is obviously satisfied with the regional status quo because it is the maintainer of the regional status quo. However, at the global level, the state can be either satisfied or dissatisfied with the global status quo depending on its foreign policy stance or goals. The case of a regional challenger is a bit more complicated because one more possibility can be added to a regional challenger - a regional challenger can be either satisfied with or dissatisfied with the regional status quo apart from the global status quo.

Since a state's status quo evaluations are involved at two different levels and dissatisfaction is one of the important conditions for the onset of war, we should consider both status quo evaluations of states when we study war, regional war in particular. We argue that not only the regional status quo evaluation but also the global status quo evaluation affects the probability of a regional war between a regional challenger and a dominant state. We also claim that when the two states' status quo evaluations are in opposite directions at both the global and regional levels, they are much more likely to go to war.

Basically, the regional status quo is subordinated to and influenced by the global order even though a regional dominant state can have some degree of autonomy in establishing and maintaining it. The regional status quo changes as a result of the power relations between a regional challenger and a regional dominant state. In particular, the changes occur through militarized conflicts between them. However, this conflict would not remain a bilateral conflict or war, especially when the two states have very different policies or views on the global status quo and the outcome of the 
conflict can affect a regional status quo significantly.

Since the change of a regional status quo can affect the global status quo or system stability, the global dominant power would not allow a regional status quo to become a menace to the stability of the global order. The global dominant power will actively or implicitly intervene in the conflict in order to maintain a regional status quo in favor of the global status quo and also to reinforce the global order by changing the regional status quo in favor of the global dominant power. In the same vein, a global challenger who is dissatisfied with the global status quo would be more likely to intervene in the conflict to make the outcome of the conflict in favor of itself. ${ }^{10)}$ In this circumstance, the possibility of global contenders' intervention in the regional conflict is high. Both a regional challenger and a dominant state can anticipate and will actively seek security help from the global contenders who have the same stance and policy on the global status quo, and the two regional states would be more likely to actively use that assistance from global contenders in order to widen their opportunities.

When a regional challenger as well as a regional dominant state seeks outside security help, its global status quo evaluation plays an important role since only a global contender who shares the same global status quo evaluation would be willing to help. Unless a global contender has any interest in the region or can share and enjoy the fruits of victory with a winner (either a regional challenger or a regional dominant state), it would not engage in a regional conflict. ${ }^{11)}$ Since the conflict between a regional challenger and a dominant state over the regional status quo can affect the interests of global contenders regarding reinforcing and/or undermining the existing global order and system stability, global contenders would either actively or implicitly support their regional friend (one of the two regional states) and attempt to make the outcome in favor of them in their global

10) Palmer and Morgan (2006) and (2007); T. Clifton Morgan and Glenn Palmer, "To Protect and to Serve: Alliances and Foreign Policy Portfolios," Journal of Conflict Resolution 47-2 (2003), pp. 180-203.

11) Vesna Danilovic, When the Stakes Are High: Deterrence and Conflict among Major Powers (Ann Arbor, MI: University of Michigan Press, 2002). 
competition. Hence, the global status quo evaluations of the two regional contenders also affect the probability of war between the two. Namely, when a regional challenger and a dominant state have not only conflicting regional status quo evaluations but also conflicting global status quo evaluations, the possibility of war between the two states will be higher than when they have the same regional and global status quo evaluations.

The rationale of our argument should become more evident by considering several possible combinations of a regional challenger and a dominant state. As we have shown above, all states have two different status quo evaluations at two different levels-regional and global. Hence, the combinations of the status quo evaluations of a regional challenger and a dominant state in a dyad can have several contingencies as shown in Table 1.

When we consider all possibilities of combinations of the two states' status quo evaluations both at the regional and global level, there are eight possible dyad combinations, and we categorize three different groups based on the directions of the status quo evaluations of the two states. They are ${ }^{12)}$ :

1) Consistent at both levels - $(1, C),(2, D)$

2) Inconsistent at both levels - (1, B), (2, A)

3) Mixed status quo evaluations at both levels - (1, A), (1, D), (2, B), (2, C)

Table 1. Regional Dyads Based on Their Status Quo Evaluations

\begin{tabular}{c|l|l}
\hline \multirow{2}{*}{$\begin{array}{c}\text { Regional Dominant } \\
\text { (RD) }\end{array}$} & Regional Status Quo Evaluation & Global Status Quo Evaluation \\
\cline { 2 - 3 } & (1) Satisfied & Satisfied \\
\hline \multirow{4}{*}{$\begin{array}{c}\text { Regional Challenger } \\
\text { (RC) }\end{array}$} & (A) Dissatisfied & Dissatisfied \\
\cline { 2 - 3 } & (B) Dissatisfied & Satisfied \\
\cline { 2 - 3 } & (C) Satisfied & Dissatisfied \\
\cline { 2 - 3 } & (D) Satisfied & Satisfied \\
\hline
\end{tabular}

The dyads $(1, C)$ and $(2, D)$ are the dyads in which the two states share the exact same status quo evaluations at both levels. In the dyad $(1, \mathrm{C})$, the

12) By definition, a dominant power is always more satisfied with the status quo than a challenger state regardless of the system level because a dominant power establishes and maintains the status quo and benefits from it. 
regional challenger (RC) is satisfied with both the regional status quo and the global status quo, and the regional dominant state (RD) is also satisfied with the global status quo. The dyad $(2, \mathrm{D})$ is similar to the dyad $(1, \mathrm{C})$. Both a regional challenger and a dominant state are satisfied with the regional status quo while both are dissatisfied with the global status quo. Hence, in these cases, the directions of the status quo evaluations of the two states at both the regional and global levels are the same and consistent between the two levels and between the two states. For these cases, the probability of war should be lower than any other case even when the regional challenger achieves the power parity, all other things being equal, because the two states share the same status quo evaluations. The challenger would not have a desire to change at the regional level because the challenger is already satisfied with the regional status quo. At the global level, even though both states are dissatisfied with the global status quo, the regional dominant state is not the challenger state's target rather they are potential or actual allies against the global states.

The dyads (1, B) and (2, A) are examples of the second category-dyads having inconsistent or opposite status quo evaluations. In contrast to the dyads $(1, C)$ and $(2, D)$, the regional challenger (RC) has the exact opposite status quo evaluations at both levels as the regional dominant state (RD). In the case of $(1, \mathrm{~B})$, the challenger $(\mathrm{RC})$ is dissatisfied with both the regional status quo and the global status quo while the dominant state (RD) is satisfied with both the global and the regional status quo. The challenger's regional dissatisfaction with the regional dominant state (RD) increases the probability of war as power transition theory expects. In addition, the two states' opposite directions of the global status quo evaluations also increase the probability of war since it has a high probability of global contenders' intervention. If the regional challenger (RD) wins the war against the regional dominant state (RD), the regional status quo will be changed. This change obviously will be favorable to the challenger itself, but will be against the global dominant power because the regional challenger is dissatisfied with the global dominant power. The global dominant power would not want this change against its interest and 
the regional dominant state also can anticipate this. Hence, the regional dominant state would ask for and can expect security help from the global power. The global dominant power also implicitly or explicitly signals to the regional dominant state (RD) a sign of security help in order to prevent a potential seed of the global system instability. In this vein, the regional dominant state is less likely to accept the demand of the regional challenger.

This rationale is also applied to the regional challenger. The change resulting from the success of the regional challenger in the regional conflict against the regional dominant state will be beneficial to a dissatisfied global challenger who attempts to alter the global status quo since this change can undermine the global status quo. Hence, a global challenger who is dissatisfied with the global order will be more likely to provide security help to the regional challenger and, with this security help, the regional challenger will be more likely to rely on military means to alter the regional status quo that is a source of disadvantage to it. Therefore, we can expect a higher probability of war in this case compared to when they share the same direction of status quo evaluations.

Dyads $(2, \mathrm{~A})$ and $(1, \mathrm{~B})$ are similar to each other except regarding one point, and we can expect a similar scenario from $(2, A)$. The difference between them is that in the dyad $(2, A)$ the directions of the global status quo evaluations of the two states are switched. In the circumstance where the regional challenger (RC) is dissatisfied with the regional order, the regional challenger $(\mathrm{RC})$ is satisfied with the global status quo while the regional dominant state (RD) is dissatisfied with the global dominant power. In this situation, the regional challenger's regional dissatisfaction plays a fundamental role to increase the probability of war. Since the regional challenger (RC) enjoys benefits at some level from the global order, the challenger can feel deprivation from the disadvantage at the regional level and try to enhance its interests by changing the regional order as its power grows. In addition, the regional challenger (RC) can expect security help from the global dominant power who has the same global status quo evaluation as the challenger. For the global dominant power, it is also beneficial for her and system stability to replace an 
unfavorable regional status quo or dominant state with a favorable status quo or a new regional dominant state. Hence, the global dominant power would actively support the regional challenger state, and with this help the regional challenger would make more aggressive demands to the regional dominant state (RD).

However, the regional dominant state (RD) that is dissatisfied with the global status quo is more likely to be desperate to defend the regional status quo because it is the only source of her benefits. Therefore, the regional dominant state is less likely to accept the challenger's demand to change. Rather, it is more likely to defend its position. In addition, with the same logic, if the regional dominant state can find outside help from a global challenger who is also dissatisfied with the global dominant power, the regional dominant state's stance will be firmer. A global dissatisfied challenger can expand its influence in the region and can build a counteralliance bloc against the global dominant power. It can be a source of undermining the global status quo and is obviously what the dissatisfied global challenger wants. Therefore, the probability of war should be higher when the regional challenger and dominant state have opposite directions of status quo evaluations at both the regional and global levels compared to when they have similar directions of status quo evaluations.

The third category is mixed cases where the regional challenger and dominant state have different status quo evaluations only at either the regional or the global level. Dyads $(1, \mathrm{D})$ and $(2, \mathrm{C})$ should be seen as having a low probability of war since the regional challenger is satisfied with the regional status quo. The only difference in the status quo evaluation is at the global level. They are less likely to go to war even though they have different status quo evaluations at the global level because they are satisfied with each other, and the conflict between them cannot change the global status quo. Both the regional challenger and the dominant state cannot expect any benefits from the conflict because the global status quo is nothing with the outcome of their conflict. Therefore, we expect a low possibility of war in this case.

The last case-dyads $(1, \mathrm{~A})$ and $(2, \mathrm{~B})$ - involves the dyads in which the 
regional challenger $(\mathrm{RC})$ and the regional dominant state $(\mathrm{RD})$ have the same direction of the global status quo evaluations while the regional challenger is dissatisfied with the regional dominant power. In these cases, we expect relatively a lower probability of war than when the two states have opposite status quo evaluations at both levels, while we expect a higher probability of war compared to the previous cases where the two states are satisfied with each other at the regional level. Since the regional challenger is dissatisfied with the regional dominant state, the basic probability of war should be seen as higher when the two states are at power parity. However, the two states, in contrast to $(1, B)$ or $(2, A)$, would find it difficult to expect outside help since their sources of outside help are the same due to their similar foreign policy positions at the global level. In these cases, global contenders are more likely to mediate the conflict before the outbreak of war since they are all friends and a fight between friends can be beneficial to or advantageous to their enemy. With this mediation, the two states are more likely to make some degree of concession to each other and the conflict would be more likely to be resolved peacefully. Therefore, the probability of war in this case would be moderate or low.

Based on the theoretical arguments shown above, we hypothesize as follows: When a regional challenger has opposite directions of status quo evaluations with a regional dominant state at both the regional and the global level, they are more likely to go to war compared to when they have consistent status quo evaluations at both levels or at only one level. ${ }^{13)}$

In the following section, we conduct a statistical test of this hypothesis.

13) In the section of theoretical discussions, we have developed the impact of the linked status quo evaluations between the regional and the global level by considering all possible categorical cases. However, the main empirical focus of this article is limited to testing whether inconsistent status quo evaluations of regional contenders affect the probability of regional war. Thus, we leave other empirical tests of specific hypotheses that can be derived from our theoretical discussion for future studies. 


\section{Research Design}

\section{Unit of Analysis and Sample}

In order to test our hypothesis, we observe dyads consisting of a dominant state and a challenger state of each regional hierarchy over ten years. We use Lemke's multiple hierarchy model in identifying a dominant and a challenger state of regional hierarchies. ${ }^{14)}$ Lemke conceptualizes and identifies twenty one local hierarchies based on states' joint capabilities of military interactions and lists a dominant and a challenger state of each hierarchy (see Appendix for a detailed list). Since his identification is plausible, we accept his identification and use his sample for our analysis. The data includes a total of 539 dyads in South America, the Middle East, the Far East, and Africa for the time period 1860 to 1990.

\section{Variables and Method}

The dependent variable of the analysis is the onset of war. We observe whether two states in a dyad go to war defined by the Correlates of War (COW) project in a given decade. Since the dependent variable is a dichotomous variable, we use logit analysis for our data analysis. In addition, we employ the natural cubic spline technique developed by Beck, Katz, and Tucker to correct the potential temporal dependency of war occurrence. ${ }^{15)}$

14) In deciding regional dominant powers and challengers, Lemke uses both GDP and the Correlates of War (COW) project's composite index of national capabilities (CINC). The CINC score combines the following factors: total population, urban population, iron and steel production, energy consumption, military personnel, and military expenditures. See J. David Singer, Stuart Bremer, and John Stuckey, "Capability Distribution, Uncertainty, and Major Power War, 1820-1965,” in Bruce Russett (ed.), Peace, War, and Numbers (Beverly Hills, CA: Sage, 1972), pp. 19-48; J. David Singer, "Reconstructing the Correlates of War Dataset on Material Capabilities of States, 1816-1985," International Interactions 14 (1987), pp. 115-32. We also consider both measures to identify regional dominant and challenger states. See Lemke (2002, ch. 4) for detailed discussions.

15) Nathaniel Beck, Jonathan N. Katz, and Richard Tucker, "Taking Time Seriously: 
The first independent variable is the power parity between the two states in a dyad. For power parity, we use the 70 percent threshold for power parity instead of the 80 percent threshold that has been used by other scholars since Organski and Kugler. ${ }^{16)}$ Our justification of this more generous threshold of power parity is in the same vein as that of Lemke. As Lemke claims, it is more uncertain among non-major power states whether a challenger reaches at the parity with a dominant state than among great powers. ${ }^{17)}$ In addition, minor states can feel their power growth more easily than major powers and can be more confident at the regional level compared to the global level. These reasons lead us to the justification that it would be better to use a more relaxed threshold for minor power relations. Therefore, the power parity is coded as one if a challenger's power is greater than 70 percent of a dominant power within a hierarchy. For this variable, we employ Lemke's GDP-based measure for national power. This data is mainly based on Penn World Tables,${ }^{18)}$ but it is also supplemented with various sources. ${ }^{19}$

In regard to satisfaction, we measure two different status quo evaluations at two different levels - regional and global levels - as our theory suggests. For the regional status quo evaluation, we use ongoing rapid military buildup following Lemke. The source of dissatisfaction of a regional challenger toward a regional dominant state at the regional level is more likely to be about specific issues. If a challenger is dissatisfied with a dominant state within a region, the most likely way for the challenger to respond or prepare for a potential conflict in order to achieve a desirable outcome would be reinforcing its military capability. In that sense, we agree with Lemke in that rapid military buildup is a better measure for a

Time-Series-Cross-Section Analysis with a Binary Dependent Variable," American Journal of Political Science 42-4 (1998), pp. 1260-88.

16) Organski and Kugler (1980).

17) Lemke (2002), p. 99.

18) For Penn World Tables, see Roberts Summers and Alan Heston, "The Penn World Table (Mark 5): An Expanded Set of International Comparisons, 1950-1988," Quarterly Journal of Economics 106-2 (1991), pp. 327-68.

19) See Lemke (2002), p. 99 for the details. 
challenger's dissatisfaction at the regional level.

We operationalize dissatisfaction at the regional level as whether a regional challenger has been experiencing ongoing rapid military buildup compared to previous time periods and whether this increase of the challenger's military buildup is greater than that of a regional dominant power. More specifically, the challenger's ongoing military buildup is measured by whether the average annual changes in military spending of the state in the time period in question is greater than that of the state prior to the given time period. Next, we compare the challenger's military buildup measure to the same measure of a dominant state within a regional hierarchy. Therefore, we code regional dissatisfaction as one only if a challenger state has had ongoing extraordinary military buildup compared to the previous time period and to the average annual increase of a dominant state's military spending in the time period in question. We use the military expenditure data of the Composite Index of National Capability (v. 3.0) of the COW project. ${ }^{20)}$

For the global status quo evaluation of a regional challenger and a regional dominant state, we observe whether a regional challenger and a dominant state, respectively, are dissatisfied with the global status quo in terms of foreign policy similarity. Since the global order is established and maintained by the global dominant power in a given time period (ten years), we use a state's weighted S scores with the global dominant power in judging the state's dissatisfaction at the global level. ${ }^{21)}$ Signorino and Ritter's S-score is a measure of similarity of foreign policy positions between two states based on two states' alliance portfolios. ${ }^{22)}$ The range of a state's S score with the global dominant power is from "-1" to "+1," and "-1" means perfect dissimilarity between a state' $\mathrm{s}$ foreign policy position and that of the global dominant power while " +1 " means perfect similarity. More specifically, we decide that a state is dissatisfied with the global

20) Singer, Bremer, and Stuckey (1972), pp. 19-48; Singer (1987), pp. 115-32.

21) Curtis Signorino and Jeffrey Ritter, "Tau-b or Not Tau-b: Measuring Similarity of Foreign Policy Positions," International Studies Quarterly 43-1 (1999), pp. 115-44.

22) Ibid. 
order only if the average of the state's annual S scores during the time period is less than the average of all states' (in the global system) annual means of S scores subtracted by one half of the standard deviations of all states' S scores.

After identifying each challenger's and each dominant power's dissatisfaction with the global status quo, based upon this, we judge whether the two states have different directions of status quo evaluation at the global level. We code the difference in the status quo evaluations of the two states at the global level as one only if 1) a challenger state is dissatisfied with the global order while a regional dominant state is satisfied with the global order or 2) a challenger state is satisfied with the global order while a regional dominant state is dissatisfied with the global order. Hence, this variable is a dichotomous variable and indicates whether a challenger and a dominant state disagree with each other on the status quo evaluations at the global level.

Based on the above regional and global status quo evaluation information of the two states, we make our key independent variable, status quo evaluation inconsistency. As mentioned earlier, we expect that two states in a dyad are more likely to go to war if the two states have totally different status quo evaluations at both the regional and global level, all other things being equal. Therefore, we code it as one if the directions of the status quo of a challenger and that of a regional dominant power are opposite both at the regional and global levels, zero otherwise. In other words, the following cases are coded one for this variable: 1) a challenger is dissatisfied with a regional dominant state and is also dissatisfied with the global order while the regional dominant state is satisfied with the global order; 2) a challenger is dissatisfied with a regional dominant state but satisfied with the global order while the regional dominant state is dissatisfied with the global order.

In order to control for the confounding effects of other potential influential factors on war occurrence, we include some control variables in our empirical model based on the findings of previous research on the outbreak of war. A series of work on the steps-to-war model by Senese and 
Vasquez has shown that the probability of war increases when both states in a dyad have outside alliances while the probability decreases when the two states are allied to each other. ${ }^{23)}$ Hence, we include two different alliance variables in our empirical model. The first alliance variable is outside alliances and is coded as one if the two states in a dyad have alliances with other states outside the dyad for the whole time period in question, zero otherwise. Another alliance variable is allied to each other in a dyad. This variable is coded as one if the two states in a dyad have any type of alliance with each other during the whole time period in question, zero otherwise. Alliance information for all alliance variables is obtained from the Alliance Treaty Obligation and Provisions (ATOP) Project. ${ }^{24)}$

Studies on the steps to war by Senese and Vasquez and other studies ${ }^{25}$ have shown that territorial disputes are one of the most important causes of the outbreak of war. Based on their findings, we also include the territorial dispute variable in our model. This variable is coded as one if the two states in a dyad have experienced a territorial dispute in a given time period, zero otherwise. We use the Militarized Interstate Dispute Data (MID v. 3.1) of the COW project ${ }^{26)}$ for this variable.

Another control variable is contiguity. Since Bremer, ${ }^{27)}$ a good deal of

23) Paul D. Senese and John A. Vasquez, "Alliances, Territorial Disputes, and the Probability of War: Testing for Interactions," in Paul F. Diehl (ed.), The Scourge of War: New Extensions on an Old Problem (Ann Arbor, MI: University of Michigan Press, 2004), pp. 189-221; Senese and Vasquez, "Assessing the Steps to War," British Journal of Political Science 35-4 (2005), pp. 607-33; Senese and Vasquez, The Steps To War: An Empirical Study (Princeton, NJ: Princeton University Press, 2008).

24) Brett A. Leeds, Jeffrey M. Ritter, Sara McLaughlin Mitchell, and Andrew G. Long, "Alliance Treaty Obligations and Provisions, 1815-1944," International Interactions 28-3 (2002), pp. 237-60.

25) Senese and Vasquez (2004), and Paul R. Hensel, "Charting a Course to Conflict: Territorial Issues and Interstate Conflict, 1886-1992," Conflict Management and Peace Science 15-1 (1996), pp. 47-73; Hensel, "Territory: Theory and Evidence on Geography and Conflict," in John A. Vasquez (ed.), What Do We Know about War (Lanham, MD: Rowman \& Littlefield, 2000), pp. 57-84.

26) Faten Ghosn, Glenn Palmer, and Stuart A. Bremer, "The MID3 Data Set, 1993-2001: Procedures, Coding Rules, and Description," Conflict Management and Peace Science 21-2 (2004), pp. 133-54.

27) Bremer, "Dangerous Dyads: Conditions Affecting the Likelihood of Interstate War, 
research has shown that states are more likely to fight with each other when they are geographically contiguous. ${ }^{28)}$ In addition, since a minor state' s ability to project its power is restrained by geographic conditions, geographical contiguity between states is an important object condition in the outbreak of war. Therefore, we use contiguity as a control variable for our model. We rely on the Directed Contiguity data (v. 3.0) from the COW project. ${ }^{29)}$ We code one for this variable if two states are contiguous on land, and zero otherwise.

The last control variable of our model is joint democracy. For the last few decades, one of the most robust findings in international relations studies is that two democracies are much less likely to go to war with one another. ${ }^{30}$ Because of the pacifying effect of joint democracy, we use joint democracy as another control variable based on the states' democracy scores. The democracy scores of states are conveyed in the POLITY IV dataset. ${ }^{31)}$ We create a dummy variable of joint democracy. This is coded as one if both annual averages of the democratic scores of two states in a dyad are six or higher during the time period based on the POLITY IV democracy scale, and zero otherwise.

1816-1965," Journal of Conflict Resolution 36-2 (1992), pp. 309-41.

28) See Senese, "Territory, Contiguity, and International Conflict: Assessing a New Joint Explanation," American Journal of Political Science 49-4 (2005), pp. 769-79; Vasquez, The War Puzzle (New York, NY: Cambridge University Press, 1993); D. Scott Bennett and Allan C. Stam, The Behavioral Origins of War (Ann Arbor, MI: University of Michigan Press, 2004).

29) Douglas M. Stinnett, Jaroslav Tir, Philip Schafer, Paul F. Diehl, and Charles Gochman, "The Correlates of War Project Direct Contiguity Data, Version 3," Conflict Management and Peace Science 19-2 (2002), pp. 58-66.

30) See Zeev Maoz and Bruce Russett, "Normative and Structural Causes of Democratic Peace, 1946-1986," American Political Science Review 87-3 (1993), pp. 624-38; Bruce Russett and John R. Oneal, Triangulating Peace: Democracy, Interdependence, and International Organizations (New York, NY: W.W. Norton, 2001); James Lee Ray, "Does Democracy Cause Peace?” Annual Review of Political Science 1 (1998), pp. 27-46.

31) Monty G. Marshall and Keith Jaggers, "Polity IV Project: Political Regime Characteristics and Transitions, 1800-2002, Dataset User's Manual,” (2002), at $<$ http://www.cidcm.umd.edu/inscr/polity $>$. 


\section{Empirical Analysis}

As we have claimed above, the onset of war between a regional challenger and a dominant state is influenced by not only the dissatisfaction with the status quo at the regional level but also the two states' global status quo evaluations and the combination of both evaluations. Hence, before testing

Table 2. Effect of Global Level Status Quo Evaluation on War Onset (Logit Results)

\begin{tabular}{|c|c|c|}
\hline Variables in Model & Coefficient & Odds Ratio \\
\hline \multicolumn{3}{|l|}{$Y=$ War Onset } \\
\hline $\begin{array}{l}\text { Difference of Status Quo Evaluation at } \\
\text { Global Level }\end{array}$ & $\begin{array}{l}2.166^{* *} \\
(.706)\end{array}$ & 8.72 \\
\hline Parity & $\begin{array}{l}3.959 * * \\
(1.280)\end{array}$ & 52.39 \\
\hline Dissatisfaction at Regional Level & $\begin{array}{l}3.005^{*} \\
(1.222)\end{array}$ & 20.18 \\
\hline Parity X Dissatisfaction & $\begin{array}{l}-2.314 \\
(1.582)\end{array}$ & .09 \\
\hline Joint Democracy & Perfect Predictor & Perfect Predictor \\
\hline Outside Alliances & $\begin{array}{l}.446 \\
(.743)\end{array}$ & 1.56 \\
\hline Allied to Each Other & $\begin{array}{l}-.768 \\
(.661)\end{array}$ & .46 \\
\hline Territorial Disputes & $\begin{array}{l}-.306 \\
(.548)\end{array}$ & .74 \\
\hline Contiguity & $\begin{array}{l}2.496 * * * \\
(.763)\end{array}$ & 12.14 \\
\hline Peace Years ${ }^{\dagger}$ & $\begin{array}{l}.024 \\
(.098)\end{array}$ & - \\
\hline Constant & $\begin{array}{l}-7.676 \\
(1.546)\end{array}$ & - \\
\hline \multicolumn{3}{|l|}{$\mathrm{N}=406$} \\
\hline $\begin{array}{l}\text { Wald } \chi^{2}(\text { d.f. })=44.96(12) \\
\text { Prob. }>\chi^{2}=.0000 \\
\text { Log Pseudolikelihood }=-43.7350 \\
\text { Pseudo } R^{2}=.3513\end{array}$ & & \\
\hline
\end{tabular}

Notes: Robust standard errors adjusted for clustering on the dyad are in parentheses.

${ }^{\dagger}$ Estimates for the three natural cubic spline variables are not reported and are not statistically significant at the .05 level.

$* * * p<.001, * * p<.01, * p<.05$ (two-tailed). 
our main hypothesis, it is useful to test whether the status quo evaluation at the global level affects the onset of local war. To begin the analysis, Table 2 demonstrates the logit analysis result of the effect of the status quo evaluation at the global level. Overall results are consistent with the expectation of our argument. The difference in the status quo evaluation at the global level between a regional challenger and a dominant state has a positive impact on the onset of war at the .01 significance level. The odds of a regional challenger and a dominant state going to war are over 8 times higher when their status quo evaluations are at opposite directions at the global level (when either a challenger is satisfied with the global status quo while a regional dominant state is dissatisfied with the global order or vice versa) compared to when they agree or have similar global status quo evaluations.

This result supports the rationale of our initial query. That is, the foreign policy similarities of both a regional challenger (RC) and a regional dominant state $(\mathrm{RD})$ with the global dominant power and/or international order also affect the onset of regional war between the two regional states although the primary concerns of the two states are local issues.

The other two variables from power transition theory confirm the findings of previous empirical studies on power transition theory. ${ }^{32)}$ Power parity between a regional challenger and a dominant state has a strong positive effect on war occurrence. In terms of the odds ratio, two states are about 52 times more likely to go to war when they are at power parity compared to when they are not at power parity. A challenger state's dissatisfaction with a regional dominant power also increases the probability of the onset of war, and the likelihood is over 20 times higher than when a challenger is satisfied. Contiguity also shows a strong positive impact on the onset of war consistent with the findings of previous studies while all other control variables, except joint democracy, are not statistically significant at the .05 level.

32) Organski and Kugler (1980); Kim (1991; 1996); Lemke and Werner (1996); Werner and Lemke (1997); and Lemke (2002). 
Table 3. Effect of Status Quo Evaluation Difference on War Onset (Logit Results)

\begin{tabular}{|c|c|c|}
\hline Variables in Model & Coefficient & Odds Ratio \\
\hline \multicolumn{3}{|l|}{$Y=$ War Onset } \\
\hline Status Quo Evaluation Difference & $\begin{array}{l}2.039^{*} \\
(.954)\end{array}$ & 7.68 \\
\hline Parity & $\begin{array}{l}3.263^{* *} \\
(1.227)\end{array}$ & 26.13 \\
\hline Dissatisfaction at Regional Level & $\begin{array}{l}1.591 \\
(1.363)\end{array}$ & 4.91 \\
\hline Parity X Dissatisfaction & $\begin{array}{l}-1.610 \\
(1.509)\end{array}$ & .20 \\
\hline Joint Democracy & Perfect Predictor & Perfect Predictor \\
\hline Outside Alliances & $\begin{array}{l}.581 \\
(.744)\end{array}$ & 1.79 \\
\hline Allied to Each Other & $\begin{array}{l}-.912 \\
(.594)\end{array}$ & .41 \\
\hline Territorial Disputes & $\begin{array}{l}-.350 \\
(.564)\end{array}$ & .70 \\
\hline Contiguity & $\begin{array}{l}2.050 * * \\
(.740)\end{array}$ & 7.77 \\
\hline Peace Years ${ }^{\dagger}$ & $\begin{array}{l}.007 \\
(.100)\end{array}$ & - \\
\hline Constant & $\begin{array}{l}-5.829 \\
(1.320)\end{array}$ & - \\
\hline \multicolumn{3}{|l|}{$\mathrm{N}=406$} \\
\hline $\begin{array}{l}\text { Wald } \chi^{2}(\text { d.f. })=57.61(12) \\
\text { Prob. }>\chi^{2}=.0000 \\
\text { Log Pseudolikelihood }=-45.2372 \\
\text { Pseudo } R^{2}=.3290\end{array}$ & & \\
\hline
\end{tabular}

Notes: Robust standard errors adjusted for clustering on the dyad are in parentheses.

${ }^{\dagger}$ Estimates for the three natural cubic spline variables are not reported and are not statistically significant at the .05 level.

$* * * p<.001, * * p<.01, * p<.05$ (two-tailed).

As our main test, Table 3 reports the logit analysis result of the effect of the status quo evaluation difference between the regional and global levels on war occurrence. The result represents a supportive finding for our hypothesis. Power parity between a regional challenger and a dominant state shows a strong positive impact on the onset of war. The odds of war 
occurrence is over 26 times higher when they are at power parity than when they are not in the condition of power parity.

It is an interesting finding that a challenger state's dissatisfaction at the regional level becomes statistically insignificant at the .05 level after introducing our key independent variable - two states' status quo evaluation inconsistency between the regional and global level - of our empirical model, while our key variable is statistically significant and shows a positive effect on the onset of war. As expected, two states' status quo evaluation inconsistency between the regional and global level demonstrates an increasing effect on the likelihood of war occurrence. In terms of the odds ratio, when the two states have totally opposite status quo evaluations at both the regional and the global level, the likelihood of going to war is about 7.6 times higher than when they have similar status quo evaluations at both levels. In other words, the probability of war is higher if a regional challenger and a dominant state disagree with respect to the regional status quo - a regional dominant state likes and wants to maintain it while a regional challenger dislikes it and wants to alter it - and the global status quo - one (either the regional challenger or regional dominant) likes the global status quo maintained by the global dominant power while the other (either a regional dominant or a challenger) dislikes it. This is the finding we expect. Regarding other control variables, contiguity shows a positive effect on the onset of war. The odds of war occurrence are over 7 times higher when two states are contiguous on land. However, the other control variables are not statistically significant at the .05 level. Joint democracy is a perfect indicator of no-war, which is the same as in the previous report.

The positive effect of status quo evaluation inconsistency between the global and regional level is made clear by the predicted probability analysis. Table 4 reports the predicted probabilities of the outbreak of war depending on various conditions. The predicted probability of war keeps increasing as additional conditions are added. The probability is only .0212 when there is no condition of power parity, regional dissatisfaction, or status quo evaluation inconsistency. However, the probability of war increases dramatically up to .1192 when all of the conditions exist and this 
is higher than a probability with any other conditions. Although the absolute probability is still low, this probability should not be ignored because the base probability is extremely low (a war is a very rare event) and the marginal increase is very significant. In short, the predicted probability analysis confirms that the inconsistent status quo evaluations between a regional challenger and a dominant state at the regional and global levels increase the likelihood of war.

Table 4. Predicted Probabilities of War Occurrence

\begin{tabular}{ll}
\hline Condition & Predicted Probability \\
\hline \multirow{2}{*}{ No Condition } & .0212 \\
& $(1.92 \mathrm{e}-13-.2122)$ \\
Parity & .0452 \\
& $(8.25 \mathrm{e}-12-.8024)$ \\
Parity + Regional Level Dissatisfaction & .0775 \\
Parity + Regional Dissatisfaction + & $(3.76 \mathrm{e}-11-.9661)$ \\
Status Quo Evaluation Difference & .1192 \\
\hline
\end{tabular}

Notes: Main entries are predicted probabilities derived from the model in Table 2, when all other variables are held at their mean values. $95 \%$ confidence intervals are in parentheses.

Predicted probabilities are calculated with CLARIFY (King, Tomz, and Wittenberg, 2000).

The base probability of war is .0284 .

These results imply that the conflict behavior of a regional challenger and a regional dominant state is not simply affected by the regional status quo or specific issues but by comprehensive and broad foreign policy orientations which are a combination of both regional and global status quo evaluations. It also can be interpreted that the international system or international order can be associated with a local conflict between regional contenders in contrast to some previous studies. ${ }^{33)}$ When a regional challenger and a regional dominant state have opposite status quo evaluations at the global level, the two states can expect outside security help and global contenders also are more likely to intervene in the conflict because by doing so they can share the fruits of the conflict. A regional

33) Bruce Bueno de Mesquita and David Lalman, "Empirical Support for Systemic and Dyadic Explanations of International Conflict,” World Politics 41-1 (1988), pp. 1-20. 
hierarchy is subordinate to the global hierarchy, and the change in the regional hierarchy can directly or indirectly affect the power distribution of the global system. Due to these factors, global contenders including the global dominant power actively watch and intervene in a regional conflict rather than take a wait-and-see attitude. These factors increase the likelihood of war between two regional contenders.

The findings also imply that the global dominant power is a vigorous manager of the global system by both changing and maintaining the global order $^{34)}$ rather than a passive keeper of the global order or system stability as previous power transition theorists think. Regional contenders know this very well and attempt to make use of these conditions. Therefore, the combination of global and regional status quo evaluations influences the likelihood of war between regional contenders.

\section{Conclusions}

This study has started to extend Lemke's multiple hierarchy model of power transition theory by introducing two different dimensions of status quo evaluations of regional contenders. Since a state's status quo evaluations are involved at two different levels - the regional and global-and a challenger's dissatisfaction is one of the important conditions for the onset of war, the study of regional war, war between regional contenders in particular, should consider both status quo evaluations of states. We argue that not only the regional status evaluation but also the global status quo evaluation affects the probability of a regional war between a regional challenger and a dominant state. We also claim that when the two states' status quo evaluations are in opposite directions, they are much more likely to go to war because the change of a regional status quo can affect the global status quo and, thus, regional conflict contending over the regional status quo is more likely to invite the intervention of global contenders. We

34) Palmer and Morgan (2006; 2007). 
have discovered the supportive empirical evidence for our argument through statistical tests.

This study shows that a state's status quo evaluation for war is more complicated. A state, a regional power contending over the regional status quo in particular, considers not only regional issues but also its stance and the opponent's stance in the global order and alignment since a state's foreign policy stance or alignment status with global contenders can widen its opportunities in the conflict. Hence, the likelihood of a regional war contending over the regional status quo is affected both by a regional challenger state's dissatisfaction with the regional dominant state and by the global status quo.

In the same vein, we can infer a systemic effect on regional conflict as we have mentioned above. The finding that two regional states' foreign policy stances or views on the global order influence the likelihood of war means that the decisions of the two states are influenced by the global order and system. Therefore, it is reasonable to argue that the international system influences regional war. Related to Kim's contribution to power transition theory, ${ }^{35)}$ this theme should be investigated more deeply. If alliance parity is associated with a systemic war, as Kim reports, global contenders will be more likely to expand their alliance blocs and, in turn, regional powers would make use of this effort of global contenders in order to enhance their regional interests (either maintaining or changing the regional status quo). This could be one reason why the global status quo evaluation of regional contenders matters in the outbreak of regional war.

Lastly, this study provides some suggestions for studies on East Asian international relations in particular. This article suggests that the future of U.S.-China relations can directly affect regional cooperation and conflict, and that this factor should be more comprehensively considered when analyzing regional issues. If, for instance, the United States and China develop constructive relations and successfully find more and more common interests, China will become a satisfied challenger at the global

35) See Kim (1991; 1992; 1996). 
level, and the cooperative relations between the United States and China will have a positive impact on East Asian states' relations. They will be more likely to mange regional issues in a more cooperative and peaceful manner since a militarized conflict between regional states would be harmful for both states' interests.

However, if U.S.-China relations become more conflictual and thus China becomes dissatisfied with the global status quo, this competition between the United States and China not only will increase the tension at the global level but also will be extended to the East Asian region. As China becomes more dissatisfied with the global status quo, it will be more likely to expand and fortify its influence in the region to confront and challenge U.S. dominance. In response to this, the United States will also attempt to prevent China from expanding its influence in the region, which can trigger a spiral of hostile competition between the United States and China. Under this circumstance, regional issues can be linked easily to the global competition between the United States and China, and the two global contenders will be more likely to make use of regional issues to expand their influence and interests, which can increase the probability of militarized conflict as our empirical finding shows. Therefore, in this context, the theoretical discussions and empirical findings provided in this study can be useful for investigating the prospect of regional conflict in this region.

\section{Appendix. List of Regional Hierarchies}

\section{South America (1860-1990)}

Northern Tier: Colombia*; Ecuador; Venezuela*

Atlantic Coast: Argentina*; Brazil; Uruguay

Pacific Coast: Chile*; Peru*

Central (after 1990): Bolivia*; Paraguay

2. Middle East (1960-1990)

Arab-Israel: Egypt*; Iraq; Israel*; Jordan; Lebanon; Syria 
Northern Rim: Iran*; Iraq; Turkey*

Arabian Peninsular (after 1971): Bahrain; Kuwait; Qatar; Saudi Arabia*; United Arab Emirates

\section{Far East (1950-1990)}

South Asia: Bangladesh; Bhutan; India*; Pakistan

South East Asia: Cambodia; Laos; South Vietnam (Republic of Vietnam, until 1975); Thailand; Vietnam (former N.

Vietnam or Democratic Republic of Vietnam)*

East Asia: China*; Japan; N. Korea; S. Korea; Mongolia; Taiwan

Asian Archipelago: Indonesia*; Malaysia; Singapore

Dyadic Local Hierarchy:

Afghanistan-Pakistan*

Burma/Myanmar-Thailand*

N. Korea-S. Korea*

4. Africa (1960-1990)

Maghreb: Algeria*; Libya; Morocco*; Tunisia

West Africa: Gambia; Guinea; Guinea Bissau; Mali; Mauritania;

Senegal*; Sierra Leone

Gulf of Guinea: Benin; Burkina Faso; Cameroon; Ghana; Ivory

Coast; Liberia; Niger; Nigeria*; Togo

Central Lowland: Central African Rep.; Chad*

Horn of Africa: Djibouti; Ethiopia*; Somalia; Sudan*

Central Highland: Burundi; Rwanda*

South Atlantic: Angola; Cameroon; Congo; Gabon; Zaire

(Democratic Republic of the Congo)*

Indian Ocean: Kenya*; Tanzania*; Uganda

Southern Africa: Botswana; Lesotho; Malawi; Mozambique; South

Africa*; Swaziland; Zambia; Zimbabwe

Notes:

1. Asterisks indicate the regional dominant state.

2. Local hierarchies are defined based on states' joint capabilities of military interactions by Lemke (2002). 


\section{REFERENCES}

Beck, Nathaniel, Jonathan N. Katz, and Richard Tucker. "Taking Time Seriously: Time-Series-Cross-Section Analysis with a Binary Dependent Variable." American Journal of Political Science 42-4 (1998).

Bennett, D. Scott and Allan C. Stam. "EUGene: A Conceptual Manual." International Interactions 26-2 (2000). . The Behavioral Origins of War. Ann Arbor, Michigan: University of Michigan Press, 2004.

Benson, Michelle. "Extending the Bounds of Power Transition Theory." International Interactions 33-3 (2007).

Bremer, Stuart A. "Dangerous Dyads: Conditions Affecting the Likelihood of Interstate War, 1816-1965." Journal of Conflict Resolution 36-2 (1992).

Bueno de Mesquita, Bruce and David Lalman. "Empirical Support for Systemic and Dyadic Explanations of International Conflict." World Politics 41-1 (1988).

Danilovic, Vesna. When the Stakes Are High: Deterrence and Conflict among Major Powers. Ann Arbor, Michigan: University of Michigan Press, 2002.

DiCcico, Jonnathan M., and Jack S. Levy. "The Power Transition Research Program: A Lakatosian Analysis," in Colin Elman and Miriam Fendius Elman (eds.), Progress in International Relations Theory: Appraising the Field. Cambridge, Massachusetts: MIT Press, 2003.

Ghosn, Faten, Glenn Palmer, and Stuart A. Bremer. "The MID3 Data Set, 1993-2001: Procedures, Coding Rules, and Description.” Conflict Management and Peace Science 21-2 (2004).

Hensel, Paul R. "Charting a Course to Conflict: Territorial Issues and Interstate Conflict, 1886-1992." Conflict Management and Peace Science 15-1 (1996). 
. "Territory: Theory and Evidence on Geography and Conflict," in John A. Vasquez (ed.), What Do We Know About War. Lanham, Maryland: Rowman \& Littlefield, 2000.

Kadera, Kelly M. "The Conditions and Consequences of Dyadic Power transitions: Deductions from a Dynamic Model," in Jacek Kugler and Douglas Lemke (eds.), Parity and War: Evaluations and Extensions of The War Ledger. Ann Arbor, Michigan: University of Michigan Press, 1996.

Kim, Woosang. "Alliance Transitions and Great Power War." American Journal of Political Science 35-4 (1991).

. "Power Transitions and Great Power War from Westphalia to Waterloo.” World Politics 45-1 (1992).

. "Power Parity, Alliance, and War from 1648 to 1975," in Jacek

Kugler and Douglas Lemke (eds.), Parity and War: Evaluations and Extensions of The War Ledger. Ann Arbor, Michigan: University of Michigan Press, 1996.

King, Gary, Michael Tomz, and Jason Wittenberg. "Making the Most of Statistical Analyses: Improving Interpretation and Presentation." American Journal of Political Science 44-2 (2000).

Kugler, Jacek and Douglas Lemke. "The Power Transition Research Program: Assessing Theoretical and Empirical Advances," in Manus I. Midlarsky (ed.), Handbook of War Studies II . Ann Arbor, Michigan: University of Michigan Press, 2000.

Leeds, Brett A., Jeffrey M. Ritter, Sara McLaughlin Mitchell, and Andrew G. Long. "Alliance Treaty Obligations and Provisions, 1815-1944.” International Interactions 28-3 (2002).

Lemke, Douglas and Suzanne Werner. "Power Parity, Commitment to Change, and War." International Studies Quarterly 40-2 (1996).

Lemke, Douglas. Regions of War and Peace. New York, New York: Cambridge University Press, 2002.

Maoz, Zeev and Bruce Russett. "Normative and Structural Causes of Democratic Peace, 1946-1986." American Political Science 
Review 87-3 (1993).

Marshall, Monty G. and Keith Jaggers. "Polity IV Project: Political Regime Characteristics and Transitions, 1800-2002, Dataset User's Manual.” (2002), at <http://www.cidcm.umd.edu/inscr/polity>.

Morgan, Clifton T. and Glenn Palmer. "To Protect and to Serve: Alliances and Foreign Policy Portfolios." Journal of Conflict Resolution 47-2 (2003).

Organski, A. F. K. World Politics. New York, New York: Alfred A. Knopf, 1958.

Organski, A. F. K. and Jacek Kugler. The War Ledger. Chicago, Illinois: University of Chicago Press, 1980.

Palmer, Glenn and T. Clifton Morgan. A Theory of Foreign Policy. Princeton, New Jersey: Princeton University Press, 2006. . "Power Transition, the Two-Good Theory, and Neorealism: A Comparison with Comments on Recent U.S. Foreign Policy.” International Interactions 33-3 (2007).

Ray, James Lee. "Does Democracy Cause Peace?" Annual Review of Political Science 1 (1998).

Russett, Bruce and John R. Oneal. Triangulating Peace: Democracy, Interdependence, and International Organizations. New York, New York: W.W. Norton, 2001.

Senese, Paul D. "Territory, Contiguity, and International Conflict: Assessing a New Joint Explanation.” American Journal of Political Science 49-4 (2005).

Senese, Paul D. and John A., Vasquez. "Alliances, Territorial Disputes, and the Probability of War: Testing for Interactions," in Paul F. Diehl (ed.), The Scourge of War: New Extensions on an Old Problem. Ann Arbor, Michigan: University of Michigan Press, 2004. . “Assessing the Steps to War." British Journal of Political Science 35-4 (2005). . The Steps To War: An Empirical Study. Princeton, New Jersey: Princeton University Press, 2008. 
Signorino, Curtis and Jeffrey Ritter. "Tau-b or Not Tau-b: Measuring Similarity of Foreign Policy Positions.” International Studies Quarterly 43-1 (1999).

Singer, J. David, Stuart Bremer, and John Stuckey. "Capability Distribution, Uncertainty, and Major Power War, 1820-1965," in Bruce Russett (ed.), Peace, War, and Numbers. Beverly Hills, California: Sage, 1972.

Singer, J. David. "Reconstructing the Correlates of War Dataset on Material Capabilities of States, 1816-1985.” International Interactions 14 (1987).

Stinnett, Douglas M. Jaroslav Tir, Philip Schafer, Paul F. Diehl, and Charles Gochman. "The Correlates of War Project Direct Contiguity Data, Version 3." Conflict Management and Peace Science 19-2 (2002).

Summers, Roberts and Alan Heston. "The Penn World Table (Mark 5): An Expanded Set of International Comparisons, 1950-1988." Quarterly Journal of Economics 106-2 (1991).

Tomz, Michael, Jason Wittenberg, and Gary King. CLARIFY: Software for Interpreting and Presenting Statistical Results. Version 2.1. Stanford University, University of Wisconsin, and Harvard University. 5 January 2003. At <http://gking.harvard.edu/>.

Tucker, Richard, BTSCS: A Binary Time-Series-Cross-Section Data Analysis Utility. Version 4.0.4. Cambridge, Massachusetts: Harvard University, 1999.

Vasquez, John A. The War Puzzle. New York, New York: Cambridge University Press, 1993.

Werner, Suzanne and Douglas Lemke. "Opposites Do Not Attract: The Impact of Domestic Institutions, Power, and Prior Commitment on Alignment Choices.” International Studies Quarterly 41-3 (1997). 